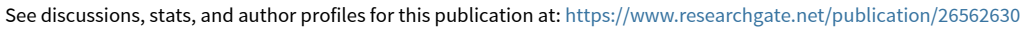

\title{
Epsilometer Test-Based Determination of Susceptibility of Clinically Important Candida Isolates to Conventional Antifungal Agents
}

Article in Journal of Medical Sciences(Faisalabad) · March 2007

DOI: 10.3923/jms.2007.374.382 · Source: DOAJ

CITATION

3 authors:

Khaled Abu-Elteen

Hashemite University

64 PUBLICATIONS 1,207 CITATIONS

SEE PROFILE

Kevin Kavanagh

National University of Ireland, Maynooth

234 PUBLICATIONS 5,987 CITATIONS

SEE PROFILE

Some of the authors of this publication are also working on these related projects:

medical microbiology View project

Phenanthroline based Transition Metal Complexes with Antibacterial Activity View project
READS

28
Mawieh Hamad

University of Sharjah

75 PUBLICATIONS 631 CITATIONS

SEE PROFILE 


\section{Research $\overline{\overline{\text { Paper }}}$}

\begin{abstract}
JMS (ISSN 1682-4474) is an International, peer-reviewed scientific journal that publishes original article in experimental \& clinical medicine and related disciplines such as molecular biology, biochemistry, genetics, biophysics, bio-and medical technology. JMS is issued eight times per year on paper and in electronic format.
\end{abstract}

\section{For further information about this article or if you need reprints, please contact:}

Khaled H. Abu-Elteen Department of Biological Sciences and Biotechnology, Faculty of Science, Hashemite University, P.O. Box 330077 , Zarqa 13133 , Jordan

Tel: (+ 962) 53903333

Fax: (+962) 53903349
J. Med. Sci., 7 (3): 374-382 1st April, 2007

\section{Epsilometer Test-Based Determination of Susceptibility of Clinically Important Candida Isolates to Conventional Antifungal Agents}

\author{
${ }^{1}$ Khaled H. Abu-Elteen, ${ }^{2}$ Mawieh A. Hamad and ${ }^{3}$ Kevin Kavanagh
}

One hundred thirty yeast clinical isolates comprised of 81 C. albicans, 22 C. tropicalis, 11 C. parapsilosis, 9 C. glabrata and 7 C. krusei were evaluated for antifungal susceptibility using the E-test. $\mathrm{MIC}, \mathrm{MIC}_{50}$ and $\mathrm{MIC}_{90}$ of amphotericin B (AMB), flucytosine (FC), fluconazole (FL), itraconazole (IT) and voriconazole (VOR) were determined at 24 and $48 \mathrm{~h}$ of incubation and compared with data obtained by the broth microdilution method. $\mathrm{MIC}$ and $\mathrm{MIC}_{90}$ determined at $24 \mathrm{~h}$ for C. albicans were: $\mathrm{AMB} \leq 0.002-0.064,0.032$, FC 0.023-2.0, 0.75, FL 0.064$>256,64$, IT $0.012-2.0,0.19$ and VOR 0.008-0.750, 0.047. Those for C. glabrata were: $\mathrm{AMB} 0.016-4.0,1.25, \mathrm{FC} \leq 0.06-4.0, \leq 0.06$, FL $1.0->256.0,64.0$, IT $0.003-4.0,1.0$ and VOR 0.047-2, 0.38. Overall, Candida species remain uniformly susceptible to AMB and FL; this not withstanding the finding that C. glabrata and C. krusei showed significant resistance to FL. MICs after $48 \mathrm{~h}$ of incubation were higher than those determined at $24 \mathrm{~h}$ of incubation; increased resistance rates and enhanced endpoint trailing particularly with FL and IT were also evident. Overall agreement between the MICs obtained by the E-test and broth microdilution methods was $\geq 86 \%$ within \pm 2 dilution for $\mathrm{AMB}, \mathrm{FL}$ and VOR for C. albicans, C. tropicalis and C. parapsilosis and $67 \%$ for C. glabrata and $52 \%$ for C. krusei for FL. Based on the $24 \mathrm{~h} \mathrm{MICs}$ determinations, resistant strains in Candida species from Jordan were encountered at a range of $8-22 \%$ against azole antifungals tested. These results suggest that the E-test is simple, inexpensive, easy both to read and interpret and has a good correlation to the CLSI microdilution test and can be conveniently incorporated and performed in a hospital-based clinical laboratory.

Key words: Antifungal susceptibility, Candida sp., broth microdilution method, E-test

${ }^{1}$ Department of Biological Sciences, Faculty of Science,

Hashemite University, Jordan

${ }^{2}$ Faculty of Medicine, Taif University, Saudi Arabia

${ }^{3}$ Department of Biology, Medical Mycology Unit,

National Institute for Cellular Biotechnology, NUI, Maynooth, Co., Ireland 


\section{INTRODUCTION}

Invasive opportunistic fungal infections have become important causes of morbidity and mortality in both critically ill and immunocompromised patients (Krcmery and Barnes, 2002; Bodey et al., 2002). Candida species are the fourth most common class of pathogens isolated from bloodstream in USA, reflecting the increased risk of Candida infections in critically ill patients (Pfaller et al., 2000a; Safdar et al., 2001). Candida species also cause a wide spectrum of diseases, including oral and vaginal thrush, severe oropharyngeal candidosis in AIDS patients where C. albicans, C. glabrata and C. tropicalis count for more than $80 \%$ of isolates from clinical infections (Akpan and Morgan, 2002). The number of available antifungal drugs was limited to amphotericin B deoxycholate $+/$ - flucytosine. In the late 1980 s, several effective and less toxic systemic antifungal agents such as ketoconazole, itraconazole and fluconazole became available (Abu-Elteen and Hamad, 2005). However, the widespread use of fluconazole during the 1990s has resulted in an increased prevalence of azole-resistant strains of Candida (Rex et al., 1997, 1993).

The Clinical and Laboratory Standards Institute (CLSI; formerly National Committee for Clinical Laboratory Standards [NCCLS]) has proposed a standardized reference broth macro- and microdilution methods for antifungal susceptibility testing of yeast (M 27-p and M 27-T, respectively) (NCCLS, 1997). The initially proposed version (M 27-P) has been revised to the approval level (M 27 A) (NCCLS, 1997). Consequently, a reference method for microdilution antifungal susceptibility testing of filamentous fungi (CLSI M 38-A) has been developed (NCCLS, 2002). Furthermore, modified less cumbersome procedures including a macroand microbroth dilution method (Cuenca-Estrella et al., 2002; Espinel-Ingroff et al., 1992), the Epsilometer (E)-test (Chang et al., 2001), flow cytometry (Lee and Kwak, 1999) and well diffusion (Magaldi et al., 2004) has been proposed as alternatives to the microbroth dilution method proposed by CLSI (NCCLS, 1997). Although flow cytometry is a rapid (2-4 h) and sensitive in vitro method for antifungal susceptibility testing (Lee and Kwak, 1999), the need for expensive and sophisticated equipment and specialized personnel to run it makes this approach less appealing than more conventional techniques. Introduction of the E-test, a novel susceptibility testing method, has greatly facilitated the antifungal susceptibility testing studies. The test involves the placement of a plastic strip (AB Biodisk, Solna, Sweden) containing a defined continuous gradient of antifungal drug on the surface of an inoculated agar (Biodisk, 1993). The test has proven to be simple and reliable for antifungal drug susceptibility testing of Candida sp. It has been reported that results generated by the E-test very closely correlate and comparable with results obtained by the broth as well as well diffusion methods (Chen et al., 1996; Pfaller et al., 2003a, b; Pfaller et al., 2000b).

Here, we report on the antifungal susceptibility of five clinically important Candida species against the most frequently used five conventional antifungal drugs in Jordan for the treatment of Candida infection- using the E-test. This is the first report on the application of the $\mathrm{E}$ susceptibility test procedure on clinical isolates from Jordan.

\section{MATERIALS AND METHODS}

Test organisms and clinical isolates: A total of 130 clinical isolates of Candida sp. were selected for testing. The collection included C. albicans $(\mathrm{n}=81)$, C. tropicalis $(\mathrm{n}=22)$, C. parapsilosis $(\mathrm{n}=11), C$. glabrata $(\mathrm{n}=9)$ and C. krusei $(\mathrm{n}=7)$. Members of this collection were obtained from oral cavity and vaginal swabs and from sputum specimen taken from diabetic patients, patients with vulvovaginal candidosis and cancer patients. Presumptive identification of yeast isolates to the species level was based on traditional methods and growth morphology, germ tube testing and color characteristics on CHROMagar Candida plates (Abu-Elteen et al., 2006) and confirmed by using API20C AUX (Bio-Merieux, Marcy I'Etoile, France). C. albicans (ATCC 36082), C. parapsilosis (ATCC 22019), C. glabrata (ATCC 90030) and C. krusei (ATCC 6258) were used as control strains.

Antifungal susceptibility testing: The E-test (AB Biodisk, Solna, Sweden) was performed to determine the Minimal Inhibitory Concentrations (MICs) of antifungal agents according to the manufacturers' instructions (Biodisk, 1993). Test strips used included: amphotericin B $(\mathrm{AMB})$, flucytosine $(\mathrm{FC})$, fluconazole (FL), itraconazole (IT) and voriconazole (VOR). Each strip present a continuous gradient of antifungal concentrations on one side and a reading scale on the opposite side. Briefly, the stored Candida sp. was subcultured on Sabouraud dextrose agar (SBA) medium, prior to testing to ensure viability and purity. Inoculums of Candida sp. were prepared from 5-6 colonies in sterile phosphate buffer saline (PBS) ( $\mathrm{pH} 7.0$ ). Following mixing, turbidity of the suspension was adjusted to match a $0.5 \mathrm{McF}$ arland 
turbidity standard. Swabs from the prepared suspension were streaked over culture plates containing RPMI-agar with $2 \%$ glucose, prepared by adding sterile liquid RPMI 1640 and buffered with $0.165 \mathrm{M}$ morpholine-propane sulphonic acid (MOPS) to $\mathrm{pH} 7.0$, solidified with $1.5 \%$ Bacto-agar (Difco Laboratories, Detroit, M.I., USA). Plates were allowed to dry for $15 \mathrm{~min}$ prior to placing five antifungal $\mathrm{E}$ test strips on the surface of media. Plates were incubated at $35^{\circ} \mathrm{C}$; MIC values were read at 24 and $48 \mathrm{~h}$ after incubation.

Interpretations of $\mathrm{M \Pi C}$ values as generated by the E-test were done according to the manufacturer's instructions. Briefly, values were read where the border of the elliptical inhibition zone intersected the scale on the strips or where there was a sharp decline in the amount of growth $(\approx 80 \%$ inhibition). In the case of growth of small colonies inside the inhibition zone, the limit of the inhibition zone was defined as the border where the colonies started to change size and the density of growth decreased ( $\approx 80 \%$ inhibition).

For comparison of data, broth microdilution test was performed according to CLSI document M 27-A (NCCLS, 1997). An inoculum concentration of $0.5 \times 10^{3}$ cells per $\mathrm{mL}$ was standardized spectrophotometrically and by quantitative plate counts. A $100 \mu \mathrm{L}$ yeast inoculum was added to each well of the microdilution trays. The final concentrations of the antifungal agents were 0.125 to $4 \mu \mathrm{g} \mathrm{mL}{ }^{-1}$ for amphotericin $\mathrm{B}, 0.007$ to $16 \mu \mathrm{g} \mathrm{mL}{ }^{-1}$ for itraconazole and voriconazole, 0.06 to $128 \mu \mathrm{g} \mathrm{mL}^{-1}$ for flucytosine and 0.12 to $128 \mu \mathrm{g} \mathrm{mL}^{-1}$ for fluconazole. The trays were incubated at $35^{\circ} \mathrm{C}$ and read after $48 \mathrm{~h}$ of incubation. MIC endpoints were determined in RPMI medium, $\mathrm{pH} 7.0$, as the lowest concentration that produced a significant decrease in turbidity relative to the control (drug-free) well (NCCLS, 1997; Abu-Elteen et al., 2006). The interpretation of antifungal resistancesusceptible category among the Candida isolates was based on the CLSI criteria of MICs breakpoints (NCCLS, 1997). The MICs $\left(\mu \mathrm{g} \mathrm{mL} \mathrm{mL}^{-1}\right)$ breakpoint categories for flucytosine of susceptible (S), intermediate susceptible (I) and resistant $(\mathrm{R})$, are $\leq 4,8-16$ and $\geq 32 \mu \mathrm{g} \mathrm{mL} \mathrm{mL}^{-1}$, respectively. Those for fluconazole of $\mathrm{S}$, susceptibility depending upon dose (S-DD) and $\mathrm{R}$ are $\leq 8,16-32$ and $\geq 64 \mu \mathrm{g} \mathrm{mL}{ }^{-1}$, respectively and for itraconazole categories of S, S-DD and R are $\leq 0.125,0.25-0.5$ and $\geq 1.0 \mu \mathrm{g} \mathrm{mL}^{-1}$, respectively. The breakpoint values for amphotericin $\mathrm{B}$ of susceptible (S) and resistant (R), are $<$ or $=2 \mu \mathrm{g} \mathrm{mL}^{-1}$, respectively.

Statistical analysis: Data analysis was carried out by means of one-way analysis of variance (ANOVA) and by multiple comparison using computer statistical analysis software (STATISTICA for Windows (1995), Stat Soft Inc, OK, USA), differences were considered as statistically significant at $\mathrm{p}<0.05$.

\section{RESULTS}

Table 1 shows the $\mathrm{MIC}$ values $\left(\mathrm{MLC}_{50}\right.$ and $\left.\mathrm{MCC}_{90}\right)$ and resistant strain percentages of clinical Candida isolates tested against conventional antifungal agents as determined by the E-test at 24 and $48 \mathrm{~h}$ incubation are listed in (Table 1). The MICs endpoint readings were easily and clearly determined for AMB, FC and VOR at both 24 and $48 \mathrm{~h}$ as very few colonies were noticed to grow within the inhibition zone (Fig. 1). In contrast, MIC inhibition zones for the FL and IT showed significant growth of small colonies within almost all inhibition zones, at both 24 and $48 \mathrm{~h}$, making the endpoint determination of MICs difficult. MIC values determined at $48 \mathrm{~h}$ were generally higher than those determined at $24 \mathrm{~h}$ for all antifungal agents tested; this although they were less pronounced for $\mathrm{AMB}$ and FC. Changes noted in the MIC patterns for both C. albicans $(\mathrm{n}=81)$ and C. tropicalis $(\mathrm{n}=22)$, at $48 \mathrm{~h}$ compared to that at $24 \mathrm{~h}$ are shown in Table 2. Such changes involved the category of susceptibility as well as the $\mathrm{MIC}$ scale. For instance, at $24 \mathrm{~h}$, resistance was noted for some isolates of C. albicans against FL and IT $(8 \%)$ and C. tropicalis against IT (14\%). At $48 \mathrm{~h}$ however, a substantial increase in resistance was observed for C. albicans against FC (10\%), FL (23\%) and IT (28\%). C. tropicalis showed increased resistance to FL (24\%) and IT (39\%) (Table 1 and 2).

For $\mathrm{AMB}, \mathrm{MIC}$ values determined at both 24 and $48 \mathrm{~h}$ were very low $\left(\leq 0.094 \mu \mathrm{gLL}^{-1}\right)$ and $\mathrm{MIC}_{50}$ and $\mathrm{MIC}_{90}$ for C. albicans after $24 \mathrm{~h}$ were 0.016 and $0.032 \mu \mathrm{g} \mathrm{mL} \mathrm{m}^{-1}$; the number of susceptible strains was 81 out of 81 $(100 \%)$. The $\mathrm{MLC}_{50}$ and $\mathrm{MLC}_{90}$ after $48 \mathrm{~h}$ were 0.023 and $0.64 \mu \mathrm{g} \mathrm{mL}{ }^{-1}$. The range of MПCs for 9 isolates of C. glabrata against $\mathrm{AMB}$ after $24 \mathrm{~h}$ was $0.016-4 \mu \mathrm{g} \mathrm{mL}^{-1}$ and the $\mathrm{MC}_{50}$ and $\mathrm{MLC}_{90}$ were 0.7 and $1.25 \mu \mathrm{g} \mathrm{mL}^{-1}$; the number of susceptible strains was 8 out of $9(89 \%)$. At $48 \mathrm{~h}, \mathrm{MIC}$ range was $0.016-8 \mu \mathrm{g} \mathrm{mL}^{-1}$ and the $\mathrm{MIC}_{50}$ and $\mathrm{MIC}_{90}$ were 1.23 and $2.21 \mu \mathrm{g} \mathrm{mL}^{-1}$ (Table 1). C. glabrata isolates showed high resistance to $\mathrm{FL}\left(\mathrm{MLC}_{50}\right.$ and $\mathrm{MIC}_{90}$ after $48 \mathrm{~h}$ were 16 and $256 \mu \mathrm{g} \mathrm{mL}^{-1}$, respectively) while C. krusei isolates showed higher MIC for FL after $48 \mathrm{~h}$ (Table 1). Voriconazole demonstrated excellent potency and broad-spectrum against all Candida species and $100 \%$ of isolates were inhibited by voriconazole at $\leq 1 \mu \mathrm{g} \mathrm{mL} L^{-1}$ (Table 1). 
Table 1: MICs of antifungal agents against Candida sp. and the percentages of resistant strains

\begin{tabular}{|c|c|c|c|c|c|c|}
\hline \multirow[b]{2}{*}{ Candida sp. (number tested) } & \multirow[b]{2}{*}{ Anti fungal agent ${ }^{\mathrm{a}}$} & \multirow[b]{2}{*}{$\begin{array}{l}\text { Reading } \\
\text { time (h) }\end{array}$} & \multirow[b]{2}{*}{ Range } & \multicolumn{2}{|c|}{$\operatorname{MICs}\left(\mu \mathrm{g} \mathrm{mL} L^{-1}\right)^{b}$} & \multirow[b]{2}{*}{$\begin{array}{l}\text { Resistant } \\
\text { strains (\%) }\end{array}$} \\
\hline & & & & $50 \%$ & $90 \%$ & \\
\hline \multirow[t]{10}{*}{ C. albicans $(81)$} & $\mathrm{AMB}$ & 24 & $\geq 0.002-0.064$ & 0.016 & 0.032 & 0 \\
\hline & & 48 & $\geq 0.002-0.094$ & 0.023 & 0.64 & 0 \\
\hline & $\mathrm{FC}$ & 24 & $0.023-2$ & 0.19 & 0.75 & 0 \\
\hline & & 48 & $0.023-\leq 32$ & 0.25 & 4.00 & 10 \\
\hline & FL & 24 & $0.064-<256$ & 0.50 & 64.00 & 8 \\
\hline & & 48 & $0.19-<256$ & 1.00 & 256.00 & 23 \\
\hline & IT & 24 & $0.012-2$ & 0.047 & 0.19 & 8 \\
\hline & & 48 & $0.012-<256$ & 0.125 & 32.00 & 28 \\
\hline & VOR & 24 & $0.008-0.750$ & 0.032 & 0.047 & 0 \\
\hline & & 48 & $0.008-64$ & 0.032 & 0.032 & 0 \\
\hline \multirow[t]{10}{*}{ C. tropicalis (22) } & $\mathrm{AMB}$ & 24 & $>0.002-0.047$ & 0.002 & 0.016 & 0 \\
\hline & & 48 & $>0.064-0.002$ & 0.006 & 0.032 & 0 \\
\hline & $\mathrm{FC}$ & 24 & $0.023-0.19$ & 0.047 & 0.125 & 0 \\
\hline & & 48 & $0.064-1.5$ & 0.094 & 0.75 & 0 \\
\hline & FL & 24 & $0.5-2$ & 1.00 & 2.00 & 0 \\
\hline & & 48 & $3-<256$ & 12.00 & 64.00 & 24 \\
\hline & IT & 24 & $0.047-1$ & 0.38 & 0.50 & 14 \\
\hline & & 48 & $0.125-<32$ & 0.75 & 12.00 & 39 \\
\hline & VOR & 24 & $0.016-1.5$ & 0.064 & 0.19 & 0 \\
\hline & & 48 & $0.019-64$ & 0.19 & 0.75 & 0 \\
\hline \multirow{10}{*}{ C. parcapsilosis (11) } & AMB & 24 & $>0.00^{\prime} 2-0.002$ & $>0.002$ & $>0.002$ & 0 \\
\hline & & 48 & $0.002-0.094$ & 0.023 & 0.64 & 0 \\
\hline & FC & 24 & $0.003-0.5$ & 0.032 & 0.047 & 0 \\
\hline & & 48 & $\geq 0.06-1$ & 0.12 & 0.25 & 0 \\
\hline & FL & 24 & $\geq 0.25-1$ & 0.50 & 1.00 & 0 \\
\hline & & 48 & $\geq 0.25-4$ & 1.00 & 2.00 & 0 \\
\hline & IT & 24 & $\geq 0.002-0.004$ & 0.002 & 0.004 & 0 \\
\hline & & 48 & $\geq 0.008-0.25$ & 0.03 & 0.12 & 0 \\
\hline & VOR & 24 & $0.008-2$ & 0.032 & 0.094 & 0 \\
\hline & & 48 & $0.008-64$ & 0.032 & 0.25 & 0 \\
\hline \multirow[t]{10}{*}{ C. glabrata (9) } & AMB & 24 & $0.016-4$ & 0.7 & 1.25 & 11 \\
\hline & & 48 & $0.016-8$ & 1.23 & 2.21 & 11 \\
\hline & $\mathrm{FC}$ & 24 & $\geq 0.06-4$ & $\geq 0.06$ & $\geq 0.06$ & 0 \\
\hline & & 48 & $\geq 0.06-4$ & $\geq 0.06$ & 0.12 & 0 \\
\hline & FL & 24 & $1-<256$ & 48.00 & 96.00 & 100 \\
\hline & & 48 & $2-<256$ & 16.00 & 256.00 & 100 \\
\hline & IT & 24 & $0.003-4$ & 0.25 & 1.00 & 22 \\
\hline & & 48 & $0.06-<8$ & 1.00 & 4.00 & 22 \\
\hline & VOR & 24 & $0.047-2$ & 0.125 & 0.38 & 0 \\
\hline & & 48 & $0.094-3$ & 0.38 & 1.00 & 0 \\
\hline \multirow[t]{10}{*}{ C. krusei (7) } & $\mathrm{AMB}$ & 24 & $0.002-0.047$ & 0.002 & 0.016 & 0 \\
\hline & & 48 & $0.002-0.064$ & 0.006 & 0.032 & 0 \\
\hline & $\mathrm{FC}$ & 24 & $\geq 0.06-0.12$ & $\geq 0.06$ & $\geq 0.06$ & 0 \\
\hline & & 48 & $\geq 0.06-1$ & 0.12 & 0.25 & 0 \\
\hline & FL & 24 & $1.5-<256$ & 48.00 & 96.00 & 100 \\
\hline & & 48 & $2-512$ & 512.00 & 512.00 & 100 \\
\hline & IT & 24 & $\geq 0.008-0.25$ & 0.03 & 0.12 & 0 \\
\hline & & 48 & $0.016-0.5$ & 0.03 & 0.25 & 0 \\
\hline & VOR & 24 & $0.016-1$ & 0.19 & 0.38 & 0 \\
\hline & & 48 & $0.016-1$ & 0.75 & 1.00 & 0 \\
\hline
\end{tabular}

aAMB, amphotericin B; FC, flucytosine; FL, fluconazole; IT, itraconazole; VOR, Voriconazole; ${ }^{\mathrm{b}} 50$ and $90 \%$; MICs at which 50 and $90 \%$ of isolates tested, respectively, are inhibited; 'Defined as follows: amphotericin B resistance, $\geq 2 \mu \mathrm{g} \mathrm{mL}^{-1}$ at $24 \mathrm{~h}$ and $\geq 4 \mu \mathrm{g} \mathrm{mL}^{-1}$ at $48 \mathrm{~h}$; flucy tosine resistance; $\geq 32 \mu \mathrm{g} \mathrm{mL}{ }^{-1}$; itraconazole resistance; $\geq 1.0 \mu \mathrm{g} \mathrm{mL}^{-1}$ and fluconazole resistance; $\geq 64 \mu \mathrm{g} \mathrm{mL}^{-1}$

The MIC range for Candida species using the microbroth dilution method and the E-test at 24 and $48 \mathrm{~h}$ are listed in Table 3. For the 81 C. albicans isolates against $\mathrm{AMB}$ using microbroth dilution method, $\mathrm{MIC}$ range was $0.125-16 \mu \mathrm{gL}^{-1}$ and the $\mathrm{MIC}_{50}$ and $\mathrm{MIC}_{90}$ were 1.5 and $2.69 \mu \mathrm{g} \mathrm{mL}^{-1}$; number of susceptible strains was $71(87.7 \%)$ and the agreement between MICs by the two methods (at \pm 2 dilutions) was 95,86 and $97 \%$ for $\mathrm{AMB}, \mathrm{FL}$ and VOR, respectively. Moreover, differences between results obtained by the E-test at 24 versus $48 \mathrm{~h}$ were statistically insignificant. C. glabrata and C. krusei were the least susceptible against FL and the agreement between MICs by the two methods were 67 and $52 \%$, respectively. The agreement between microbroth dilution 


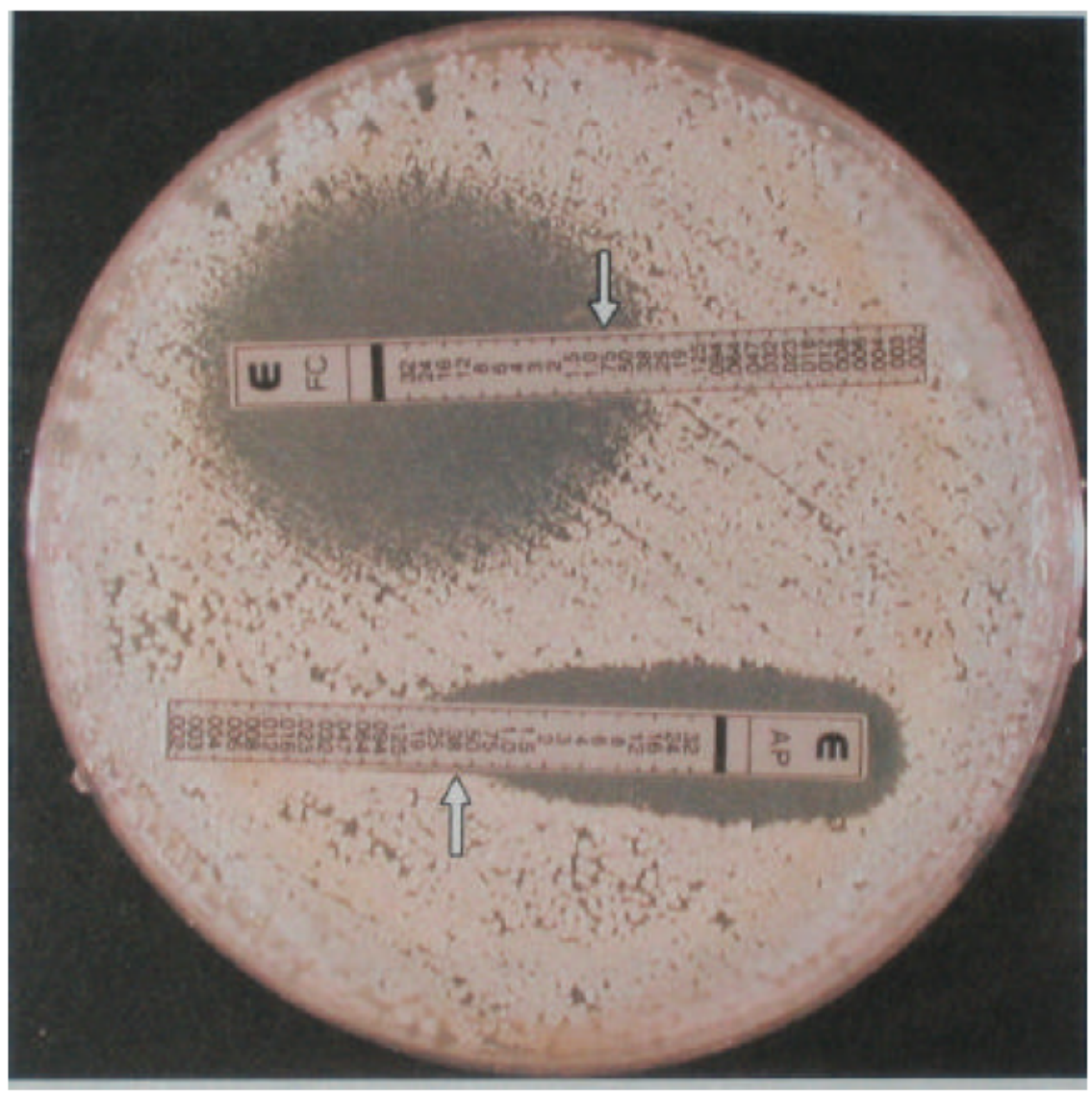

Fig. 1: Amphotericin B (AP) and flucytosine (FC) E-test patterns for C. albicans. Clear inhibition zone (ellipse) on RPMI agar. The numbers on the scale correspond to the antifungal concentrations on the strip (in $\mu \mathrm{g} \mathrm{mL}^{-1}$ )

Table 2: Observed changes in MICs determinations at $48 \mathrm{~h}$ compared to $24 \mathrm{~h}$ incubation

\begin{tabular}{|c|c|c|c|}
\hline \multirow[b]{2}{*}{ Antifungal drug } & \multirow[b]{2}{*}{ Scale changes in MICs at $48 \mathrm{vs} .24 \mathrm{~h}$} & \multicolumn{2}{|c|}{ Number $(\%)$ of isolates showing changes in } \\
\hline & & C. albicans $(\mathrm{n}=81)$ & C. tropicalis $(\mathrm{n}=22)$ \\
\hline \multirow[t]{3}{*}{ Amphotericin B } & No or within 2-scales higher & $74(91)$ & $20(91)$ \\
\hline & 3-6 higher & $4(5)$ & $2(9)$ \\
\hline & 7-9 higher & $3(4)$ & - \\
\hline \multirow[t]{4}{*}{ Flucytosine } & No or within 2-scales higher & $70(86)$ & $9(41)$ \\
\hline & 3-6 higher & $3(4)$ & $11(50)$ \\
\hline & $7-9$ higher & $4(6)$ & $2(9)$ \\
\hline & From $S$ to $R$ & $4(6)$ & - \\
\hline \multirow[t]{5}{*}{ Fluconazole } & No or within 2-5 scales higher & $55(68)$ & $9(41)$ \\
\hline & 7-9 higher & & $4(18)$ \\
\hline & $\leq 10$ higher & $26(32)$ & $9(41)$ \\
\hline & From $S$ to $S-D D$ & - & $7(32)$ \\
\hline & From $S$ to $\mathrm{R}$ & $24(30)$ & $7(32)$ \\
\hline \multirow[t]{7}{*}{ Itraconazole } & No or within 2 scale higher & $56(69)$ & $14(64)$ \\
\hline & 3-6 higher & $5(6)$ & - \\
\hline & 7-9 higher & $3(4)$ & $4(18)$ \\
\hline & $\leq 10$ higher & $17(21)$ & $4(18)$ \\
\hline & From $S$ to $S-D D$ & $11(14)$ & $2(9)$ \\
\hline & From $S$ to $R$ & $11(14)$ & - \\
\hline & From S-DD to $\mathrm{R}$ & 3(4) & $6(27)$ \\
\hline
\end{tabular}

aS, susceptible; $R$, resistant; I, intermediate susceptible; S-DD, susceptibility dependent up on dose 
Table 3: In vitro activity of amphotericin B (AMB), fluconazole (FL) and voriconazole (VOR) against Candida species as determined by micro-broth dilution method and E-test method

\begin{tabular}{|c|c|c|c|c|c|c|c|}
\hline $\begin{array}{l}\text { Candida species } \\
\text { (number tested) }\end{array}$ & $\begin{array}{l}\text { Antifungal } \\
\text { agents }\end{array}$ & Method & Range & $\mathrm{MIC}_{50}$ & $\mathrm{MIC}_{90}$ & $\begin{array}{l}\text { No. of } \\
\text { susceptible }^{b}(\%)\end{array}$ & $\begin{array}{l}\% \text { agreement } \\
\pm 2 \text { dilutions } \\
\end{array}$ \\
\hline \multirow[t]{9}{*}{ C. albicans (81) } & \multirow[t]{3}{*}{ AMB } & Microbroth & $0.125-16$ & 1.50 & 2.69 & $71(87.7)$ & \multirow[t]{3}{*}{95.0} \\
\hline & & E-test 24 & $\leq 0.002-0.064$ & 0.016 & 0.032 & $81(100.0)$ & \\
\hline & & E-test 48 & $\leq 0.002-0.094$ & 0.023 & 0.64 & $81(100.0)$ & \\
\hline & \multirow[t]{3}{*}{ FL } & Microbroth & $0.25-64$ & 14.90 & 26.80 & $74(91.3)$ & \multirow[t]{3}{*}{86.0} \\
\hline & & E-test 24 & $0.064->256$ & 0.50 & 64.00 & $78(96.3)$ & \\
\hline & & E-test 48 & $0.19->256$ & 1.00 & 256.00 & $79(97.5)$ & \\
\hline & \multirow[t]{3}{*}{ VOR } & Microbroth & $0.031-16$ & 0.031 & 0.031 & $79(97.5)$ & \multirow[t]{3}{*}{97.0} \\
\hline & & E-test 24 & $0.008-0.750$ & 0.032 & 0.047 & $81(100.0)$ & \\
\hline & & E-test 48 & $0.008-64$ & 0.032 & 0.032 & $81(100.0)$ & \\
\hline \multirow[t]{9}{*}{ C. tropicalis (22) } & \multirow[t]{3}{*}{ AMB } & Microbroth & $\leq 0.125-2$ & 0.50 & 2.00 & $16(72.7)$ & \multirow[t]{3}{*}{90.0} \\
\hline & & E-test 24 & $<0.002-0.047$ & 0.002 & 0.016 & $22(100.0)$ & \\
\hline & & E-test 48 & $<0.002-0.064$ & 0.006 & 0.032 & $22(100.0)$ & \\
\hline & \multirow[t]{3}{*}{ FL } & Microbroth & $\leq 0.125-2$ & 0.50 & 2.00 & $14(63.6)$ & \multirow[t]{3}{*}{87.0} \\
\hline & & E-test 24 & $0.5-2$ & 1.00 & 2.00 & $22(100.0)$ & \\
\hline & & E-test 48 & $3->256$ & 12.00 & 64.00 & $20(90.9)$ & \\
\hline & \multirow[t]{3}{*}{ VOR } & Microbroth & $0.031-32$ & 0.031 & 0.125 & $18(81.8)$ & \multirow[t]{3}{*}{88.2} \\
\hline & & E-test 24 & $0.016-1.5$ & 0.064 & 0.19 & $22(100.0)$ & \\
\hline & & E-test 48 & $0.019-64$ & 0.19 & 0.75 & $22(100.0)$ & \\
\hline \multirow[t]{9}{*}{ C. parapsilosis (11) } & \multirow[t]{3}{*}{$\mathrm{AMB}$} & Microbroth & $\leq 0.125-2$ & 0.50 & 1.57 & $9(81.8)$ & \multirow[t]{3}{*}{96.5} \\
\hline & & E-test 24 & $<0.002-0.002$ & $<0.002$ & $<0.002$ & $11(100.0)$ & \\
\hline & & E-test 48 & $0.002-0.094$ & 0.023 & 0.64 & $11(100.0)$ & \\
\hline & \multirow[t]{3}{*}{ FL } & Microbroth & $0.25-1$ & 0.50 & 1.00 & $10(91.0)$ & \multirow[t]{3}{*}{98.1} \\
\hline & & E-test 24 & $\leq 0.25-1$ & 0.50 & 1.00 & $11(100.0)$ & \\
\hline & & E-test 48 & $\leq 0.25-4$ & 1.00 & 2.00 & $11(100.0)$ & \\
\hline & \multirow[t]{3}{*}{ VOR } & Microbroth & $0.031-2$ & 0.031 & 0.125 & $10(91.0)$ & \multirow[t]{3}{*}{98.1} \\
\hline & & E-test 24 & $0.008-2$ & 0.032 & 0.094 & $11(100.0)$ & \\
\hline & & E-test 48 & $0.008-64$ & 0.032 & 0.25 & $11(100.0)$ & \\
\hline \multirow[t]{9}{*}{ C. glabrata (9) } & $\mathrm{AMB}$ & Microbroth & $2-4$ & 1.57 & 2.83 & $9(100.0)$ & 98.0 \\
\hline & & E-test 24 & $0.016-4$ & 0.70 & 1.25 & $8(89.0)$ & \\
\hline & & E-test 48 & $0.016-8$ & 1.23 & 2.21 & $8(89.0)$ & \\
\hline & FL & Microbroth & $2-64$ & 8.00 & 64.00 & $5(55.5)$ & 67.0 \\
\hline & & E-test 24 & $1<256$ & 48.00 & 96.00 & $3(33.3)$ & \\
\hline & & E-test 48 & $2->256$ & 16.00 & 256.00 & $1(11.1)$ & \\
\hline & VOR & Microbroth & $0.031-2$ & 0.125 & 1.00 & $8(88.8)$ & 98.2 \\
\hline & & E-test 24 & $0.047-2$ & 0.125 & 0.38 & $9(100.0)$ & \\
\hline & & E-test 48 & $0.094-3$ & 0.38 & 1.00 & $9(100.0)$ & \\
\hline C. krusei (7) & $\mathrm{AMB}$ & Microbroth & $0.5-8$ & 1.6 & 2.87 & $6(85.7)$ & 98.1 \\
\hline & & E-test 24 & $0.002-0.047$ & 0.002 & 0.016 & $7(100.0)$ & \\
\hline & & E-test 48 & $0.002-0.064$ & 0.006 & 0.032 & $7(100.0)$ & \\
\hline & FL & Microbroth & $0.125-64$ & 16.00 & 64.00 & $4(57.1)$ & 52.0 \\
\hline & & E-test 24 & $1.5-<256$ & 48.00 & 96.00 & $1(14.3)$ & \\
\hline & & E-test 48 & $2-512$ & 512.00 & 512.00 & $0(0.0)$ & \\
\hline & VOR & Microbroth & $0.031-1$ & 0.25 & 0.50 & $6(85.7)$ & 95.5 \\
\hline & & E-test 24 & $0.016-1$ & 0.19 & 0.38 & $7(100.0)$ & \\
\hline & & E-test 48 & $0.016-1$ & 0.75 & 1.00 & $7(100.0)$ & \\
\hline
\end{tabular}

a 50 and $90 \%$; MICs at which 50 and $90 \%$ of isolates tested, respectively, are inhibited; Defined as follows: amphotericin B resistance; $\geq 2 \mu \mathrm{gL}{ }^{-}$at $24 \mathrm{~h}$ and $\geq 4 \mu \mathrm{g} \mathrm{mL}^{-1}$ at $48 \mathrm{~h}$ and fluconazole resistance, $\geq 64 \mu \mathrm{g} \mathrm{mL}^{-1}$

method and the E-test for VOR against C. glabrata and C. kruse i were 98.2 and $95.5 \%$, respectively (Table 3 ).

\section{DISCUSSION}

Based on the observations made by this study, several important points can be concluded. Consistent with previous studies (Araj et al., 1998; Birinci et al., 2001; Colombo et al., 1995; Kronvall and Karlsson, 2001) the endpoint determination of MПCs are easier to read for amphotericin B, flucytosine (Fig. 1) and voriconazole than for fluconazole and itraconazole. This is mainly due to the frequent presence of yeast colonies growing within the inhibition zones of azoles. The exact reason as to why the trailing endpoints problem persists in the case of azoles remains obscure. The consistent persistence of trailing endpoints in the case of azoles irrespective of the clinical isolate tested, even those which show no trailing effects with other classes of antifungal, suggests that the problem is unlikely to be related to defective manufacturing of the test kit. It is possible that the apparent less-finely graded effects of azoles may partially explain this phenomenon. This is supported by the observation that introduction of certain modifications to the test media of the E-test has proved to be useful in minimizing azole-associated endpoint trailing 
(Pfaller et al., 1998). Manufacturers of the E-test have previously suggested the use of one of five different solidified media for antifungal susceptibility testing of yeast. Consistent with previous data (Espinel-Ingroff, 1994; Pfaller et al., 1998) the RPMI agar with $2 \%$ glucose used in this study seems to yield results that correlate well with those attained the broth microdilution (86-98\%, <2 dilutions). This is particularly true in the case of testing for susceptibility against flucytosine and ketoconazole. The rate of agreement between the E-test and CLSI reference method results in tests on RPMI agar was similar to that obtained in other studies (Ruhnke et al., 1996; St-Germain et al., 2001; Wanger et al., 1995).

The duration of incubation prior to reading the MICs is different with antifungal susceptibility tests. The CLSI macro-and microbroth dilution methods are determined at $48 \mathrm{~h}$ incubation, compared with the $24 \mathrm{~h}$ incubation for E-test agar method. In this study, the E-test MICs were determined at both 24 and $48 \mathrm{~h}$. It is clear that whereas MIC determinations taken at $24 \mathrm{~h}$ were easy to read and interpret, determinations taken at $48 \mathrm{~h}$ showed more trailing endpoints and higher MICs; this is especially true for itraconazole (Table 2). Significant discrepancies in MICs findings between 24 versus $48 \mathrm{~h}$ incubations have been previously reported (Araj et al., 1998; Chang et al., 2001). Contradictory to these findings, a previous report has suggested that similar MIC values were attained by the E-test at either 24 or $48 \mathrm{~h}$ (Ruhnke et al., 1996). Yet another study has indicated that a $48 \mathrm{~h}$ incubation period prior to reading yields better results (Espinel-Ingroff, 1994). Colombo et al. (1995) has suggested that a $24 \mathrm{~h}$ incubation period is not always enough for accurately determining E-test MICs in the case of $C$. parapsilosis. Reconciling these conflicting results could mainly rest upon the standardization of the type of media to be used.

The CLSI reference method for Candida species has provided a starting point for the development of a standard method for testing of antifungal agents. In agreement with published reports (Fidel et al., 1999; Sewell et al., 1994; Wanger et al., 1995), data obtained by the E-test correlated more nicely with those obtained by the broth reference method for C. albicans and other Candida species against amphotericin B, fluconazole and voriconazole at $24 \mathrm{~h}$ than at $48 \mathrm{~h}$ (Table 3). Wanger et al. (1995) has demonstrated that the E-test is superior to the broth macrodilution reference method as a means of distinguishing amphotericin B-resistant/susceptible isolates of Candida species. Sewell et al. (1994) has also reported more consistent $\mathrm{MIC}$ readings for C. albicans against fluconazole at $24 \mathrm{~h}(93 \%)$ than at $48 \mathrm{~h}(79 \%)$. Determination of the MICs breakpoints at $48 \mathrm{~h}$ for fluconazole and itraconazole against C. albicans and C. tropicalis revealed higher resistance rates than those determined at $24 \mathrm{~h}$ (Table 2).

Although resistance of Candida species to amphotericin B is considered as uncommon (Abu-Elteen and Hamad, 2005; Fidel et al., 1999), it has been previously reported for C. lusitaniae (St-Germain et al., 2001). The MICs ranges for amphotericin B in this study against $C$. albicans, $C$. tropicalis and $C$. parapsilosis remained very low even at $48 \mathrm{~h}\left(\leq 0.094 \mu \mathrm{g} \mathrm{mL}{ }^{-1}\right)$, indicating the absence of resistance to amphotericin $\mathrm{B}$ in clinical isolates tested. This although, the MIC for a single isolate of C. glabrata was $\geq 4 \mu \mathrm{g} \mathrm{m}^{-1}$. Earlier studies have indicated that C. krusei, C. glabrata and C. lusitaniae were less susceptible in vitro to amphotericin $\mathrm{B}$ than other Candida species (Majoros et al., 2002). While only $8 \%$ of C. albicans isolates were found to be resistant to fluconazole, it was $22 \%$ in the case of C. glabrata (Table 1). This is in agreement with the proposition that resistance of C. albicans to fluconazole appears to be associated with long-term treatment with this drug (Abu-Elteen, 2001).

\section{ACKNOWLEDGMENT}

This study was supported by research grant, deanship of scientific research, The Hashemite University. We thank all the staff at the Clinical Microbiology Division, Jordan University Hospital for their valuable help.

\section{REFERENCES}

Abu-Elteen, K.H., 2001. Increased incidence of vulvovaginal candidiasis caused by Candida glabrata in Jordan. Japn. J. Infect. Dis., 54: 103-107.

Abu-Elteen, K.H. and M. Hamad, 2005. Antifungal Agents for Use in Human Therapy. Fungi: Biology and Applications, Kavanagh, K. (Ed.). Wiley and Sons, UK., pp: 191-217.

Abu-Elteen, K.H., M. Hamad and S.A. Salah, 2006. Prevalence of oral Candida infections in diabetic patients. Bahrain Med. Bull., 28: 12-17.

Akpan, A. and R. Morgan, 2002. Oral candidiasis: A review. Postgrad. Med. J., 78: 455-459.

Araj, G.F., N.K. Daher and Z.A. Tabbarah, 1998. Antifungal susceptibility of Candida isolates at the American University of Beirut Medical Center. Int. J. Antimicrob. Agents, 10: 291-296.

Biodisk, A.B., 1993. E-test Technical Guide No. 4: Antifungal Susceptibility Testing of Yeasts. Solna, Sweden. 
Birinci, A., A. Sanic and B. Durupinar, 2001. Determination of minimum inhibitory concentrations of Candida species isolated from vaginal swab specimens by using broth macrodilution and E-test. J. Chemother., 13: 43-46.

Bodey, G., M. Mardani, H. Hanna, M. Boktour, J. Abbas, E. Girgawy, R. Hachem, D. Kontoyiannis and I. Raad, 2002. The epidemiology of Candida glabrata fungemia in immunocompromised patients with cancer. Am. J. Med., 112: 380-385.

Chang, H.C., J.J. Chang, S.H. Chang, A.H. Huang, T.L. Wu, M.C. Lin and T.C. Chang, 2001. Evaluation of E-test for direct antifungal susceptibility testing of yeasts in positive blood cultures. J. Clin. Microbiol., 39: 1328-1333.

Chen, S.C.A., M.L. O'Donnell, S. Gordon and G.L. Gilbert, 1996. Antifungal susceptibility testing using the E-test: Comparison with broth macrodilution technique. J. Antimicrob. Chemother., 37: 265-273.

Colombo, A.L., F. Barchiesi, D.A. McGough, A.W. Fothergill and M.G. Rinaldi, 1995. Evaluation of the E-test system versus amicrotitre broth method for antifungal susceptibility testing of yeasts against fluconazole and itraconazole. J. Antimicrob. Chemother., 36: 93-100.

Cuenca-Estrella, M., W. Lee-Yang, M.A. Ciblak, B.A. Arthington-Skaggs, E. Mellado, D.W. Warnock and J.L. Rodriguez-Tudela, 2002. Comparative evaluation of NCCLS M27-A and EUCAST broth microdilution procedures for antifungal susceptibility testing of Candida species. Antimicrob. Agents Chemother., 46: 3644-3647.

Espinel-Ingroff, A., C.W. Kish, T.M. Kerkering, R.A. Fromtling, K. Bartizal, J.N. Galgiani, K. Villareal, M.A. Pfaller, T. Gerar-Den, M.G. Rinaldi and A. Fothergill, 1992. Collaborative comparison of broth macrodilution and microdilution antifungal susceptibility tests. J. Clin. Microbiol., 30: 3138-3145.

Espinel-Ingroff, A., 1994. E-test for antifungal susceptibility testing of yeast. Diag. Microbiol. Infect. Dis., 19: 217-220.

Fidel, P.L., J.A. Vasquez and J. Sobel, 1999. Candida glabrata: Review of epidemiology, pathogenesis and clinical disease with comparison to C. albicans. Clin. Microbiol. Rev., 12: 80-96.

Krcmery, V. and A.J. Barnes, 2002. Non-albicans Candida sp. causing fungemia: Pathogenicity and antifungal resistance. J. Hosp. Infect., 50: 243-260.

Kronvall, G. and I. Karlsson, 2001. Fluconazole and voriconazole multidisk testing of Candida species for disk test calibration and $\mathrm{M \amalg C}$ estimation. J. Clin. Microbiol., 39: 1422-1428.
Lee, W. and Y. Kwak, 1999. Antifungal susceptibility testing of Candida species by flow cytometry. J. Korean Med. Sci., 14: 21-26.

Magaldi, S., S. Mata-Essayag, C. Hartung, C. Perez, M.T. Colella, C. Olaizola and Y. Ontiveros, 2004. Well diffusion for antifungal susceptibility testing. Int. J. Infect. Dis., 8: 39-45.

Majoros, L., G. Kardos, I. Pocsi and B. Szabo, 2002. Distribution and susceptibility of Candida species isolated in the medical university of Debrecen. Acta Microbiol. Immunol. Hung., 49: 351-361.

National Committee for Clinical Laboratory Standards, 1997. Reference Method for Broth Dilution Antifungal Susceptibility Testing of Yeasts. Approved Standard M27-A. NCCLS, Wayne, Pennsylvania.

National Committee for Clinical Laboratory Standards, 2002. Reference Method for Broth Dilution Antifungal Susceptibility Testing of Filamentous Fungi. Approved Standard M38-A. NCCLS, Wayne, Pennsylvania.

Pfaller, M.A., S.A. Messer, A. Karlsson and A. Bolmstrom, 1998. Evaluation of the Etest method for determining fluconazole susceptibilities of 402 clinical yeast isolates by using three different agar media. J. Clin. Microbiol., 36: 2586-2589.

Pfaller, M.A., R.N. Jones, G.V. Doern, H.S. Sader, S.A. Messer, A. Houston, S. Coffman, R.J. Hollis and the SENTRY Participant Group, 2000a. Bloodstream infections due to Candida species: SENTRY antimicrobial surveillance program in North America and Latin America, 1997-1998. Antimicrob. Agents Chemother., 44: 747-751.

Pfaller, M.A., S.A. Messer, A. Houston, K. Mills, A. Bolmstrom and R.J. Jones, 2000b. Evaluation of the E-test method for determining voriconazole susceptibilities of 312 clinical isolates of Candida species by using three different agar media. J. Clin. Microbiol., 38: 3713-3717.

Pfaller, M.A., D.J. Diekema, S.A. Messer, L. Boyken, R.J. Hollis, R.N. Jones and the International Fungal Surveillance Participant Group, 2003a. In vitro activities of voriconazole, posaconazole and four licensed systemic antifungal agents against Candida species infrequently isolated from blood. J. Clin. Microbiol., 41: 78-83.

Pfaller, M.A., D.J. Diekema, S.A. Messer, L. Boyken and R.J. Hollis, 2003b. Activities of fluconazole and voriconazole against 1,586 recent clinical isolates of Candida species determined by broth microdilution, disk diffusion and Etest methods: Report from the ARTEMIS global antifungal susceptibility program, 2001. J. Clin. Microbiol., 41: 1440-1446. 
Rex, J.H., M.A. Pfaller, M.G. Rinaldi, A. Polak and J.N. Galgiani, 1993. Antifungal susceptibility testing. Clin. Microbial. Rev., 6: 367-381.

Rex, J.H., M.A. Pfaller, J.N. Galgiani, M.S. Bartett, A. Espinel-Ingroff, M.A., Ghannoum, M. Lancaster, F.C. Odds, M.G. Rinaldi, T.J. Walsh and A.L. Barry, 1997. Development of interpretive breakpoints for antifungal susceptibility testing: Conceptual framework and analysis of in vitro-in vivo correlation data for fluconazole, intraconazole and Candida infections. Clin. Infect. Dis., 24: 235-247.

Ruhnke, M., A. Schmidt-Westhausen, E. Engelmann and M. Trautmann, 1996. Comparative evaluation of three antifungal susceptibility test methods for Candida albicans isolates and correlation with response to fluconazole therapy. J. Clin. Microbiol., 34: 3208-3211.

Safdar, A., V. Chaturvedi, E.W. Cross, S. Park, E.M. Bernard, D. Armstrong and D. Perlin, 2001. Prospective study of Candida species in patients at a comprehensive cancer center. Antimicrob. Agents Chemother., 45: 2129-2133.
Sewell, D.L., M.A. Pfaller and A.L. Barry, 1994. Comparison of broth macrodilution, broth microdilution and E-test antifungal susceptibility tests for fluconazole. J. Clin. Microbiol., 32: 2099-2102.

St-Germain, G., M. Laverdiere, R. Pelletier, A.-M. Bourgault, M. Libman, C. Lemieux and G. Noel, 2001. Prevalence and antifungal susceptibility of 442 Candida isolates from blood and other normally sterile sites: Results of a 2 year (1996 to 1998) multicenter surveillance study in Quebec. Canada. J. Clin. Microbiol., 39: 949-953.

Wanger, A., K. Mills, P.W. Nelson and J.H. Rex, 1995. Comparison of E-test and National Committee for Clinical Laboratory Standards broth macrodilution method for antifungal susceptibility testing: Enhanced ability to detect amphotericin B-resistant Candida isolates. Antimicrob. Agents Chemother., 39: 2520-2522. 